This item was submitted to Loughborough's Research Repository by the author.

Items in Figshare are protected by copyright, with all rights reserved, unless otherwise indicated.

\title{
Air-jet textured yarns: the effects of process and supply yarn parameters on the properties of textured yarns
}

\section{PLEASE CITE THE PUBLISHED VERSION}

http://trj.sagepub.com/

\section{PUBLISHER}

Sage (๑) Textile Research Institute)

\section{VERSION}

AM (Accepted Manuscript)

\section{PUBLISHER STATEMENT}

This work is made available according to the conditions of the Creative Commons Attribution-NonCommercialNoDerivatives 4.0 International (CC BY-NC-ND 4.0) licence. Full details of this licence are available at: https://creativecommons.org/licenses/by-nc-nd/4.0/

\section{LICENCE}

CC BY-NC-ND 4.0

\section{REPOSITORY RECORD}

Demir, Ali, Memis Acar, and Gordon R. Wray. 2019. "Air-jet Textured Yarns: The Effects of Process and Supply Yarn Parameters on the Properties of Textured Yarns”. figshare. https://hdl.handle.net/2134/22034. 


\title{
Air-Jet Textured Yarns: The Effects of Process and Supply Yarn Parameters on the Properties of Textured Yarns
}

\author{
DEMIR, M. ACAR, AND G. R. WRAY \\ Loughborough University of Technology, Department of Mechanical Engineering, \\ Loughborough, Leicestershire. LEI I J TU, England
}

\begin{abstract}
Characteristics of air-jet textured yarns are determined by the instability, linear density, and strength, together with structural properties such as loop size, loop frequency, and degree of entanglement. Such characteristics are affected by various process parameters and supply yarn properties. The effects of these parameters on the final yarn properties have been investigated using instability, linear density, and strength tests, together with SEM photographs for visual assessment of the yarn structure. Optimizing any given yarn property almost always affects other yarn characteristics, and therefore this must be remembered when selecting suitable process parameters and supply yarns for specific end uses. For a given texturing nozzle and conditions, there is an optimum filament fineness and number of filaments that can be textured effectively.
\end{abstract}

The air-jet texturing process produces yarns similar to spun yarns in terms of their appearance and physical characteristics. An air-jet textured yarn and a cotton yarn of approximately the same linear density are shown in Figure I to illustrate their visual similarity. This similarity arises from the unique air-jet texturing process in which a flat synthetic multifilament yarn is given a spun-like structure with a compact core and surface loops occurring at irregular intervals along its length. Air-jet textured yarns therefore find application in numerous textile products varying from apparel to industrial fabrics $(8,9,13,15]$.

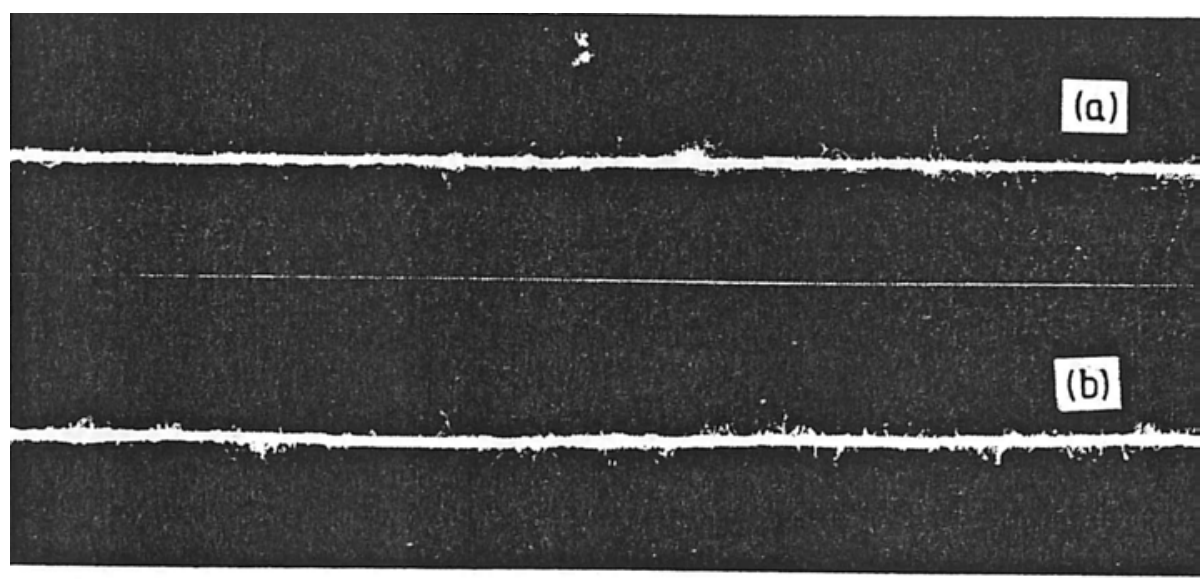

FIGURE I. Visual comparison of a cotton yam with an air-jet textured yam. 
The basic principles of the air-jet texturing process have been reported in many publications $[1,4,12,16]$. These principles are, for convenience, summarized here with the aid of Figure 2 , which illustrates the basic requirements of' air-jet texturing. The process involves the "overfeed" principle, where the multifilament sup- ply yarn is fed into the texturing nozzle at a greater speed rate than it is taken away. To achieve this degree of overfeed, the yarn passes through the feed roller sys- tem FR 1 or FR2 faster than it does through the delivery roller system DR. The overfed filaments enter the nozzle and are blown out from the exit end. They are converted into textured yarn by the supersonic, turbulent air jet. The textured yarn is then stabilized between the delivery rollers DR and take-up rollers TR. This "stabilizing extension" is created by the faster rotation of the take-up rollers.

Figure 2 shows the feed, delivery and stabilizing zones. In the stabilizing zone, a stabilizing extension of 2-6\% is applied to the yarn to mechanically remove the loose loops to improve yarn stability. The supply yarn is normally wetted just before it is fed into the nozzle to produce better textured yarns. An impact element at the nozzle exit is optionally used to facilitate better texturing. We have confined this investigation to the effects of the process and supply yarn parameters on the properties of air-jet textured yarns.

\section{Properties of Air-Jet Textured Yarns}

\section{INSTABILITY}

Although air-jet textured yarns are in general not prone to lose their bulk, even under the high tensions encountered in further textile processes and during wear, some of the loops may be pulled out under working tensions.

Loops that can be pulled out easily would be a dis- advantage in fabric forming processes, since the bulk of the yarn could be reduced and the possibility of fabric irregularity increased. A quality control test is therefore required to determine the stability of yams. Such tests, known as instability tests, involve applying known tension to the textured yarn, measuring the extension of the yam, and expressing this instability in terms of percent extension. We have critically analyzed several known instability test methods in an earlier work [5] in which we also recommended a standard instability test method.There we concluded that instability tests alone would yield misleading information regarding the yam, and that such tests should be supported by further tests and visual assessment of the yarn structure. In this paper, we will therefore support the instability test results with linear density and strength tests, together with microscopic visual assessment of yarn structure.

\section{INCREASE I N LINEAR DENSITY}

Air-jet texturing causes longer lengths of synthetic filaments to be compacted into shorter lengths with an entangled, stable structure. This shortening causes the volume and linear density of the yarn to increase (linear density can be defined as the mass per $u$ nit length of a yam).

Theoretically, we expect that the increase in linear density will be equal to the amount of overfeed, regardless of the process and the supply yarn parameters. Nevertheless, this theoretical expectation is never met in practice due to both the on-line stabilizing process and the winding-up tension. Since a well textured yarn will resist the stabilizing and winding-up tensions, the loops will stay intact within the well entangled core, and consequently its linear density will be higher than that of a poorly textured yarn. This therefore implies that the amount of increase in linear density is influenced by both 
the process itself and those supply yam parameters affecting the degree of entanglement and loop formation.

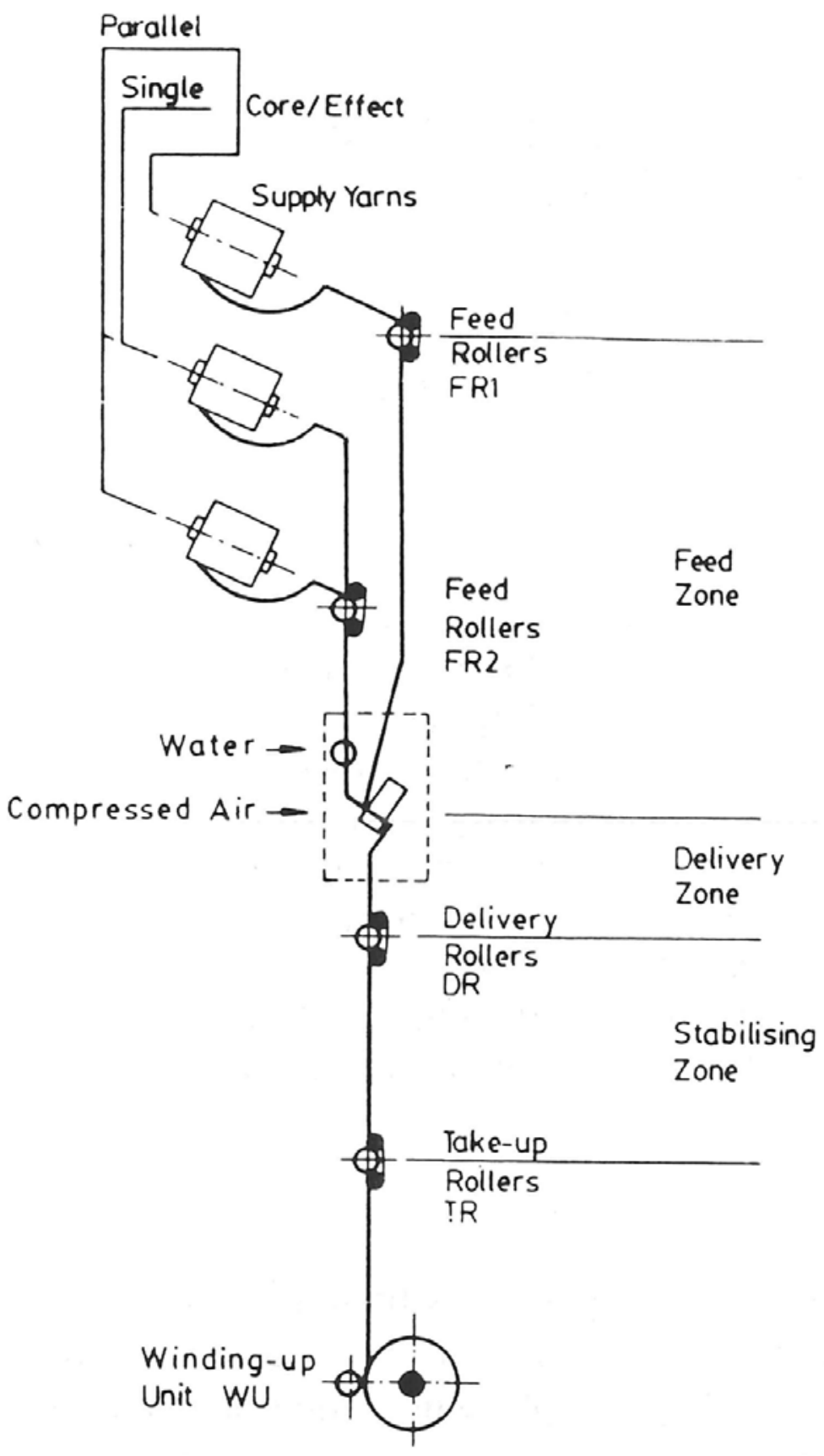

FIGURE 2. The basic requirements of the air-jet texturing process.

\section{STRENGTH}

Rozmarynowska and Godek [14] in 1966 and also very recently Kollu [12] have disclosed the findings of their research on the effects of the air-jet texturing process on individual filaments. The former researchers used physico-mechanical tests such as SEM scanning, strength measurement, birefringence, and crystallite orientation tests. The latter used only SEM scanning and strength measurements on individual filaments before and after texturing. Both have come to the same conclusion that the air-jet 
texturing process, however severe it may be (up to 5 bar $^{1}$ air pressures in 1966 and up to 11 bar pressures in 1986), caused no damage on the individual filaments in the form of cracks, local cross-sectional shrinking (thinning), or even chip formation on the filament surface. Consequently, one can conclude that any decrease in strength after texturing results solely from the entanglement of the originally parallel arrangement of the constituent filaments of the supply yarn.

Comparisons of the load elongation curves (Figure 3) of the supply (untextured) and textured yarns reveal striking differences. All of the filaments in a supply yarn simultaneously share the applied load to the yarn, and they first deform elastically. When the load is increased beyond the elastic limit, all of the filaments are then plastically deformed, exhibiting an increasing strength under this increasing load (i.e., hardening) up to the yield point where they start to elongate rapidly. When the stress in an individual filament exceeds its breaking stress, it will break regardless of the other filaments' conditions. Therefore, in a supply yarn, the filaments break singly at different times, probably due to slight variations in their diameter, and some of the filaments appear to elongate more than others. Nevertheless, for the purpose of the strength tests, the load that causes most of the filaments to break is taken as the breaking load for the yarn, and the corresponding elongation is regarded as the breaking elongation.

Textured yarns, however, exhibit totally different load elongation characteristics. Since the filaments are randomly entangled and some of these local entanglements and loops are removed under the applied load, the deformation of a textured yarn starts with permanent elongation. No hardening of the textured yarns occurs as the loading increases, because none of the individual filaments are continuously subjected to the applied load during the entire test period. All filaments exhibit loops and entangled sections intermittently along their lengths, but these are separated by straight portions of filaments. At any section of the yarn, at any particular instance, only these straight portions will resist the applied load. However, when the loops associated with these particular filaments have been opened under the applied load, their effective lengths are increased; consequently some other, less straight slack filaments in the same region may become subject to the applied load and in turn contribute to carrying it.

It is most likely that within the length of yarn tested, a particular section will be more effectively entangled than the rest and will have fewer load carrying filaments; these will be surrounded by filaments exerting lateral forces that increase the interfilament friction at this section. These load bearing, firmly entangled fil- aments will rapidly reach the breaking point simultaneously within a very short time, and consequently an almost instantaneous breakage of the yarn will occur at this section. The load-elongation curves of an air- jet textured yarn and a spun staple cotton yarn are very similar as shown in Figure 3 , suggesting that other physical characteristics of these yarns may also be similar.

From the foregoing, one can see that a good quality air-jet textured yarn, i.e., one with many small, com- pact, entangled loops, will also exhibit a large decrease in tenacity (tenacity can be described as the maximum specific stress that is developed in a tensile test to rupture) when compared with the straight filament supply yarn from which it is produced. In other words, the higher the reduction in yarn tenacity, the better the textured yarn structure.

${ }^{1}$ All the pressures reported in this paper are gauge pressures. Note that $1 \mathrm{bar}=10^{5}$ $\mathrm{N} \mathrm{m}^{-2}=1$ atmosphere. 


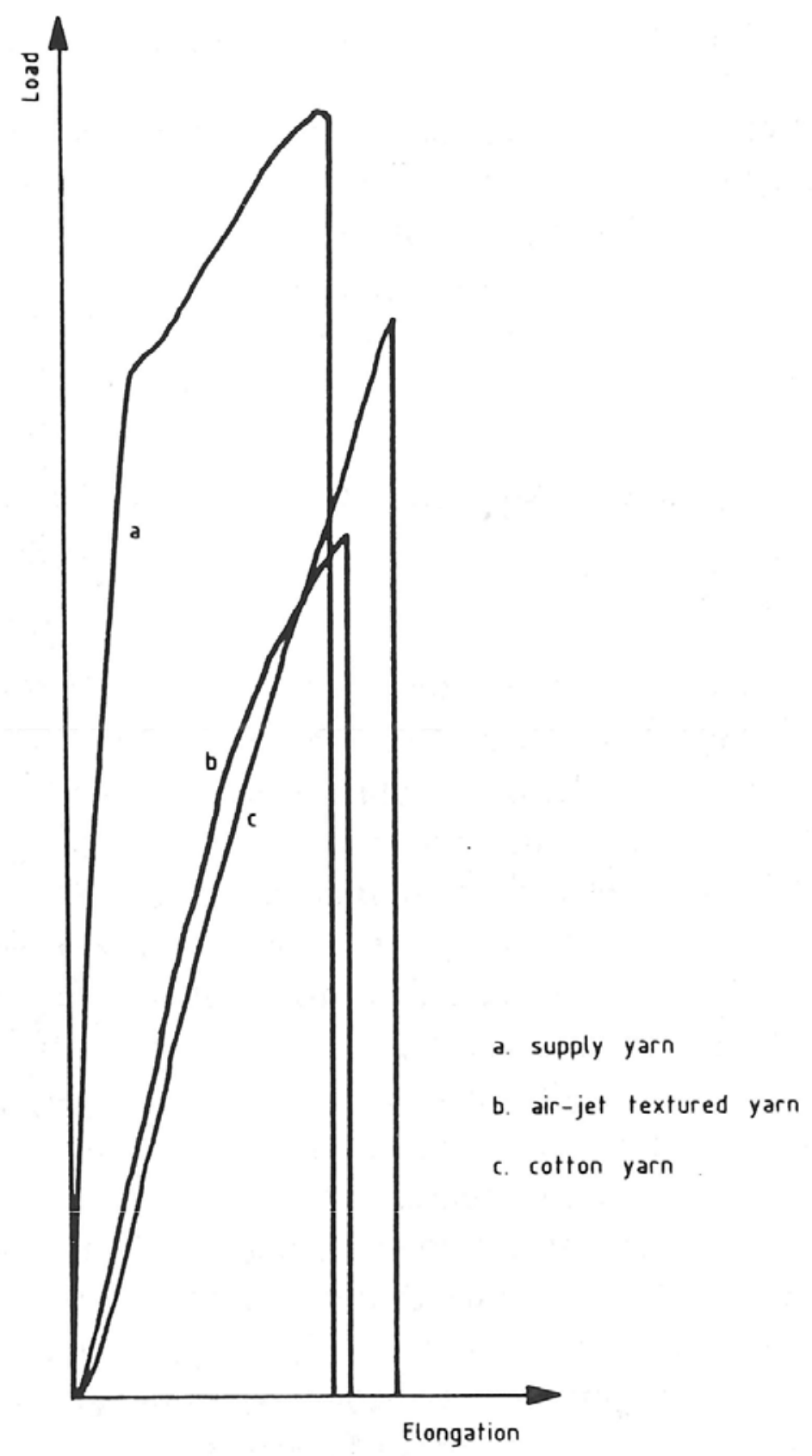

FIGURE 3. Comparison of stress-strain curves of (a) untextured, (b) air-jet textured, and (c) cotton yarns.

\section{Test Plan}

Process parameters, (e.g., air pressure, texturing speed, overfeed, stabilizing extension, wet or dry processing, and the use of an impact element) together with supply yarn parameters (e.g., the material, linear density per filament, number of filaments, filament cross-sectional shape, and applied spin finish) all play an important role in determining the final properties of air-jet textured yarns, (eg., instability, linear density, strength, bulk, and the size and frequency of loops). The effects of these parameters on the instability, linear density, and strength of the textured yarns are ascertained in the next sections, where SEM photographs of typical yarns are used to illustrate the visual surface characteristics of these textured yarns. 
A purpose-built single-head texturing machine was used to investigate the process parameters, mainly with a Heberlein T 100 HemaJet texturing nozzle [11]. Heberlein standard-core [10] and T341 HemaJets [11] together with Taslan type XIV [7] nozzles were also used. The process parameters were $10 \%$ to $30 \%$ over- feed by increments of $5 \%$, texturing speed varying from $200 \mathrm{~m} / \mathrm{min}$ to $600 \mathrm{~m} / \mathrm{min}$ by increments of $100 \mathrm{~m} / \mathrm{min}$, varying air pressure from 5 bar to 9 bar by increments of I bar, and stabilizing extensions in the range of $0-10 \%$ with increments of $2 \%$. Processing conditions of $20 \%$ overfeed, 400 $\mathrm{m} / \mathrm{min}$ texturing speed, and 7 bar air pressure, with a one liter/hour water application to the supply yarn, together with a 4\% stabilizing ex- tension were chosen as reference conditions. The T100 HemaJet texturing nozzle was used at these reference conditions without the impact element. Whenever one of the processing parameters was varied to investigate its effect on the yarn properties, the other parameters were kept at the reference conditions.

Polyamide and polyester were the only two yarn materials used. The filament linear density ranged from $1.67 \mathrm{dtex}$ to $6.8 \mathrm{dtex}$, while the number of filaments was kept approximately constant. In order to ascertain the effects of total yarn linear density (i.e., number of filaments), a 110 dtex 66-filament polyester yarn was folded to form 220, 330, and $440 \mathrm{dtex}$ yarns. The properties of the supply yarns used are given in Table I.

Having conditioned the textured yarns in the laboratory atmosphere for over 24 hours, we measured the instability on the Instron tensile testing machine in compliance with the test method we had recommended in an earlier paper [5], testing ten specimens for each type of yarn taken from randomly chosen sections of yarn packages. We also tested strength on the Instron tensile testing machine, again using ten random specimens, to obtain the average breaking load, elongation, and tenacity. Linear density calculation involved weighing 200 meters of yarn that had been measured under a slight tension, which did not remove any entanglements.

Different supply yarns have different tenacities and breaking elongations (Table I); thereby giving absolute tenacity values that would not be informative for comparison purposes. We therefore calculated the percent decrease in tenacities from the experimental results, and these are presented in a graphical format.

TABLE I. The properties of supply yarns used.

\begin{tabular}{lllllll}
\hline Material & Source & $\begin{array}{l}\text { Yarn linear } \\
\text { density, dtex }\end{array}$ & $\begin{array}{l}\text { No. of } \\
\text { filaments }\end{array}$ & $\begin{array}{l}\text { Filament linear } \\
\text { density, dtex }\end{array}$ & $\begin{array}{l}\text { Tenacity, } \\
\text { g/dtex }\end{array}$ & $\begin{array}{l}\text { Elongation } \\
\text { at } T_{2}^{a}, \%\end{array}$ \\
\hline Polyester & ICI & 110 & 66 & 1.67 & 3.64 & 0.52 \\
Polyester & Dupont & 156 & 68 & 2.30 & 4.94 & 1.8 \\
Polyamide & Dupont & 167 & 68 & 2.45 & 4.25 & 0.54 \\
Polyester & ICI & 175 & 66 & 2.65 & 3.96 & 0.59 \\
Polyester & ICI & 220 & 132 & 1.67 & 3.83 & 0.56 \\
Polyester & ICI & 234 & 60 & 3.90 & 4.40 & 1.34 \\
Polyester & ICI & 330 & 198 & 1.67 & 3.55 & 0.56 \\
Polyester & ICI & 440 & 264 & 1.67 & 3.58 & 0.55 \\
Polyester & Dupont & 470 & 68 & 6.80 & 7.42 & 1.16 \\
\hline \multicolumn{2}{l}{ Tension corresponding to the value of tension used in measuring the instability of textured yarns. }
\end{tabular}




\section{Effects of Process Parameters}

\section{AIR PRESSURE}

As the air pressure is increased, the flow velocity, which is the main driving force that opens up the fil- aments to enable them to entangle and texture, also increases. The nonuniformity and turbulence of the air flow are also enhanced by increasing air pressures [6]. An improved texturing of the yarn is therefore expected at higher pressures. One might also anticipate a more stable entanglement, i.e., less instability for yarns textured at high pressures, but Figure 4a depicts a very slight increase in the instability of air-jet textured yams as the pressure increases. From a comparison of the SEM photographs of two yarns textured at the two extremes of pressure, we see that yarn textured at 5 bar contains larger but fewer loops, whereas yarn textured at 9 bar shows a compact yarn core and a greater number of loops due to the improved texturing conditions. The slightly increased instability at higher pressures probably arises from the greater number of loops, in- creasing the likelihood of loop removal, but in no way can this increased instability be interpreted as a degradation of the texturing quality. The ensuing considerations of other properties such as the linear density increase and the decrease in tenacity substantiate this argument.
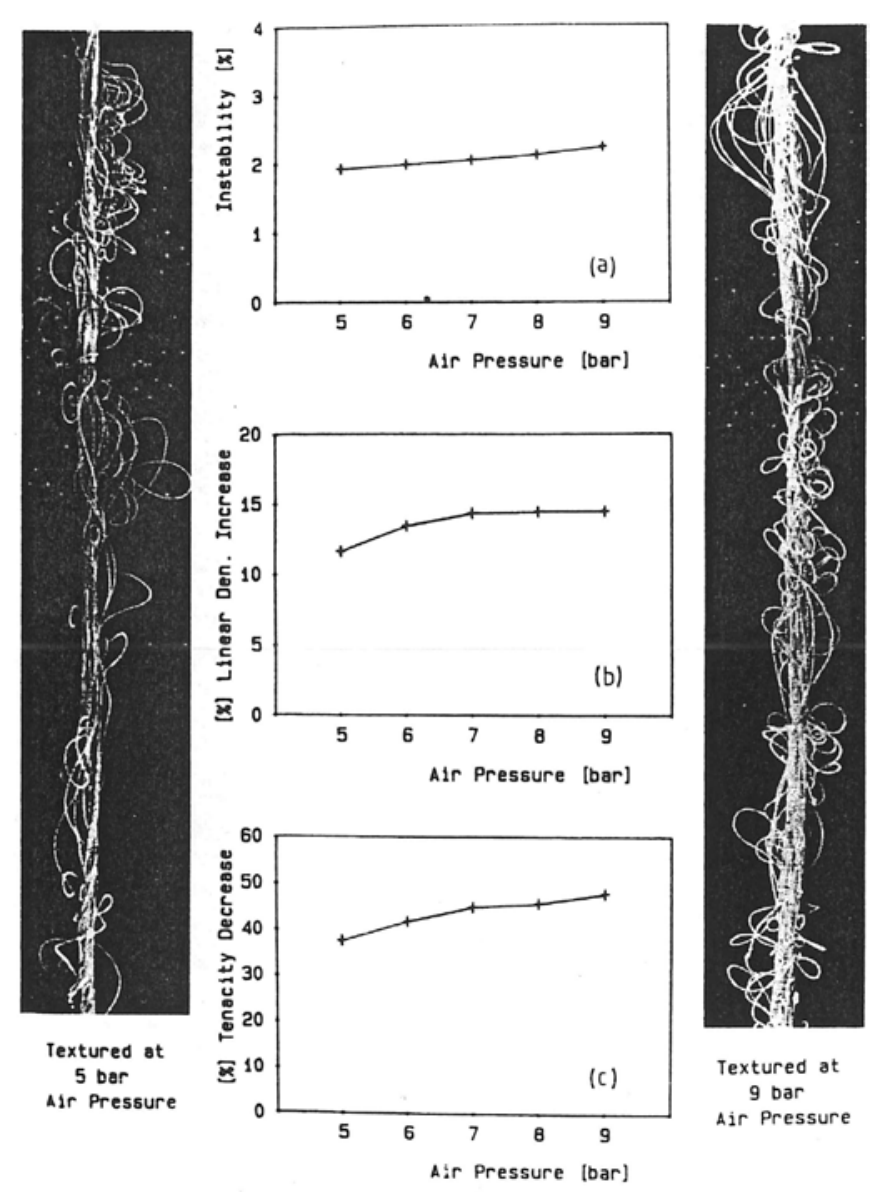

FIGURE 4. Effects of air pressure on the properties of air-jet textured yams. 
Since the amount of overfeed is kept constant at 20\%, any variation in the linear density of the yarn must be caused by better entanglement and loop formation at higher air pressures. Figure $4 \mathrm{~b}$ indicates that the linear density increase of the textured yarn increases from $12 \%$ at 5 bar to $14.5 \%$ at 7 bar, with a very small increase when the pressure is increased beyond this value. These results are typical for the supply yarn and the texturing nozzle used (the Heberlein T100 HemaJet) and cannot be generalized for other nozzles. For example, the T341 HemaJet and Taslan XIV nozzles produce textured yarns with linear densities that increase almost linearly with increasing air pressures.

Figure 4c shows that the yarns textured at 5 bar exhibit approximately $60 \%$ of the supply yarn tenacity. When the air pressure is further increased to 9 bar, the reduction in tenacity reaches approximately 50\%. This reduction in yarn strength follows from the increased numbers of loops, as depicted by the SEM photographs, which in turn reduces the number of load bearing fil- aments. This causes a reduced strength, as we argued previously.

\section{OVERFEED}

When the overfeed is as low as $10 \%$, the excess lengths of filament available to form loops and arcs are indeed small. Consequently, the texturing is poor, with very few loops on the surface and a slight reorientation in the core of the yarn, as shown in the SEM photograph in Figure 5. It exhibits a low level of in- stability because of the presence of more straight, unlooped load-bearing filament portions, but it would be unacceptable for many end uses.

As the overfeed is increased, more excess lengths of filament are available to form loops, which tend to cover the yarn surface. This increases the instability of the yarn (Figure 5a) without discrediting its acceptability as we discussed in the section on air pressure. Highspeed shadowgraphs of the emerging air jet during the texturing process have revealed that the flow be- comes more disturbed as the overfeed is increased. Consequently the texturing power of the jet decreases at higher overfeeds and, as seen in the SEM photo- graphs of a $30 \%$ overfeed textured yam (Figure 5), its surface is covered with many slack and large loops. For the given supply yam and reference process conditions, the overfeed that yields suitable texturing from the loop appearance viewpoint varies between $15 \%$ and $25 \%$, but higher overfeeds may as well be deployed for special purposes such as core and effect, fancy and slub yams.

At low overfeeds, the excess lengths of filaments are insufficiently long to form stable loops and arcs. On the other hand, as the overfeed is increased beyond the capability of a particular nozzle, effective entanglement of the filaments is unattainable. Therefore, for any particular nozzle, there is a range of overfeed over which effective texturing can be achieved. Figure $5 \mathrm{~b}$ shows that the overfeed has paramount influence on the linear yarn and process parameters are acceptable; a desired linear density can be obtained by varying the amount of overfed filaments introduced to the nozzle.

Figure 5c shows that at $10 \%$ overfeed, only a $29 \%$ decrease in tenacity occurs due to the poor entanglement and loop formation. In the resultant yam, most of the filaments are approximately straight and hence can carry a greater load. As the overfeed is increased up to $20 \%$, the effectiveness of texturing is rapidly enhanced and, due to better filament entanglement, the tenacity of the yam is correspondingly decreased by $45 \%$. Above $20 \%$ overfeed; the rate of tenacity decrease is not as high because of the less effective texturing referred to above. 

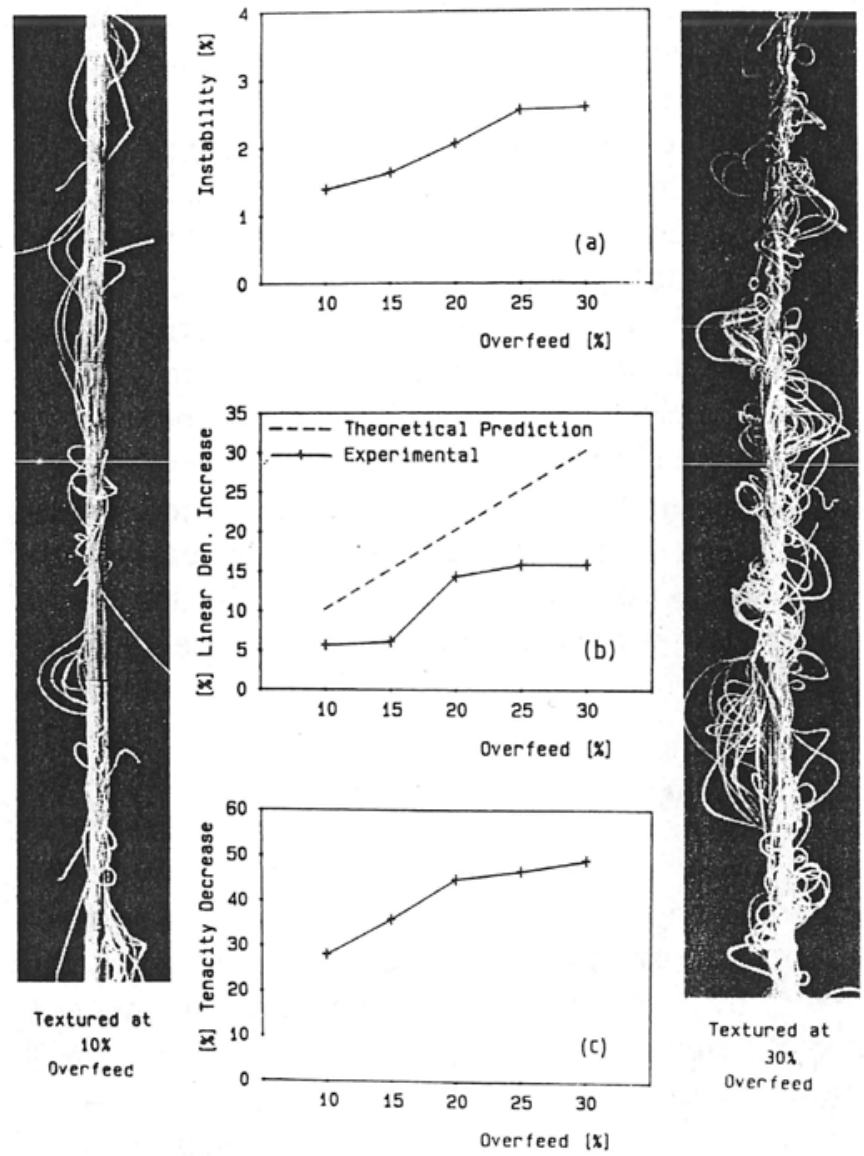

FIGURE 5. Effects of overfeed on the properties of air-jet textured yams.

\section{TEXTURING SPEED}

Figure 6a reveals only a very slight increase in yam instability with increasing texturing speeds. Since the resultant forces and torques on the filaments are mainly generated by the relative velocity between the filaments and the surrounding air flow [2], higher forces and torques are exerted on the individual filaments at lower texturing speeds. These greater fluid forces cause a better entanglement and a more firmly fixed loop formation. As the texturing speed is increased, the filament speed is also increased and the resultant forces therefore decrease. Consequently the texturing becomes less effective, thereby resulting in large and unstable loop formation as depicted by the SEM photograph of yam textured at $600 \mathrm{~m} / \mathrm{min}$.

For the particular nozzle used, the texturing at $400 \mathrm{~m} / \mathrm{min}$ is almost as effective as at 200 $\mathrm{m} / \mathrm{min}$ (Figures 6b and c), although at speeds greater than $400 \mathrm{~m} / \mathrm{min}$, the texturing quality is markedly reduced due to large and unstable loop formation. Only approximately one-third of the overfed lengths of filaments supplied could be retained in the yam at $600 \mathrm{~m} / \mathrm{min}$ texturing speed. At $200 \mathrm{~m} / \mathrm{min}$ texturing speed, however, approximately three-quarters of the overfed lengths appear to be fixed in the yam, which exhibits stable loops and a highly entangled core structure. 

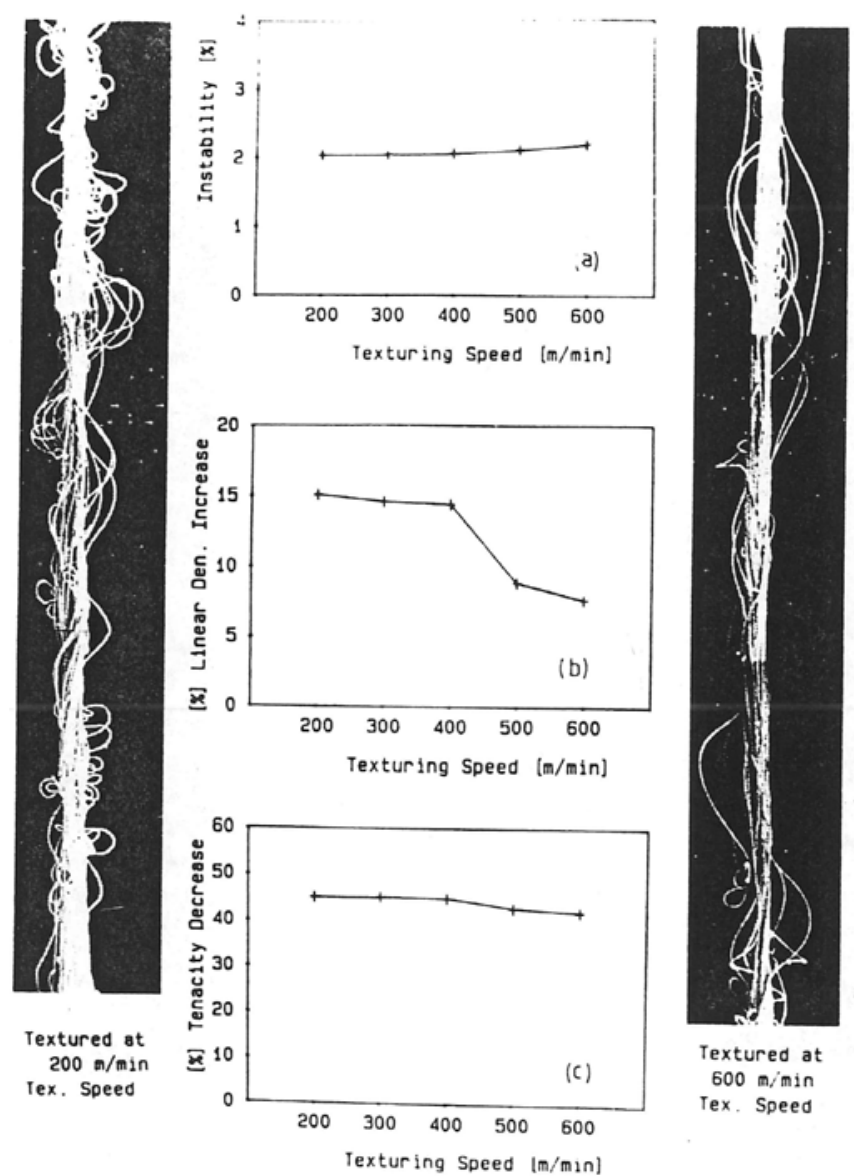

FIGURE 6. Effects of texturing speed on the properties of air-jet textured yarns.

\section{STABILIZING EXTENSION}

The purpose of the stabilizing extension, which is performed on-line on the machine subsequent to the texturing zone, is to pull out those loops that are not firmly fixed to the core of the yam. The level of this extension usually varies from $2 \%$ to $6 \%$, because at higher levels, permanent yam damage or even breakage can occur. For the purpose of our investigation, how- ever, we varied the stabilizing extension from 0 to $10 \%$.

Figure $7 \mathrm{a}$ illustrates a steady decrease in instability with increasing stabilizing extension. This is obviously due to the removal of large and loose loops on the yam prior to the application of increasing stabilizing extensions. At 10\% stabilizing extension, very few loose loops stay intact in the core of the yarn as illustrated on the SEM photograph (Figure 7). The figure shows that some of the loops were broken up to form free fiber ends due to the high tension buildup in the yarn. Further evidence for this was the accumulation of fluff around the take-up rollers. We therefore recommend that the stabilizing extension should not be so high as to cause broken filament ends, and a range of about $2 \%-4 \%$ seems reasonable for the particular supply yarn and process conditions used.

Figure $7 \mathrm{~b}$ shows the experimental linear density in- crease with increasing stabilizing extensions, together with the theoretically predicted linear density increase, which is the overfeed (20\% in this case) minus the amount of stabilizing extension. Since all linear density measurements have inevitably been done under a slight tension, some of the loops and entanglement of air-jet textured yarns may have been removed by the effect of this tension, particularly for low stabilizing extensions (less than $2.5 \%$ for the conditions considered). At higher stabilizing extensions, the loops and filament entanglement resist the applied 
tension. The yarn extends partially elastically, so that when the load is re- moved it recovers some of the extension and therefore possesses a higher linear density than theoretically predicted.

Figure 7c indicates that the amount of stabilizing extension applied during the process has little effect on the resultant yarn tenacity.
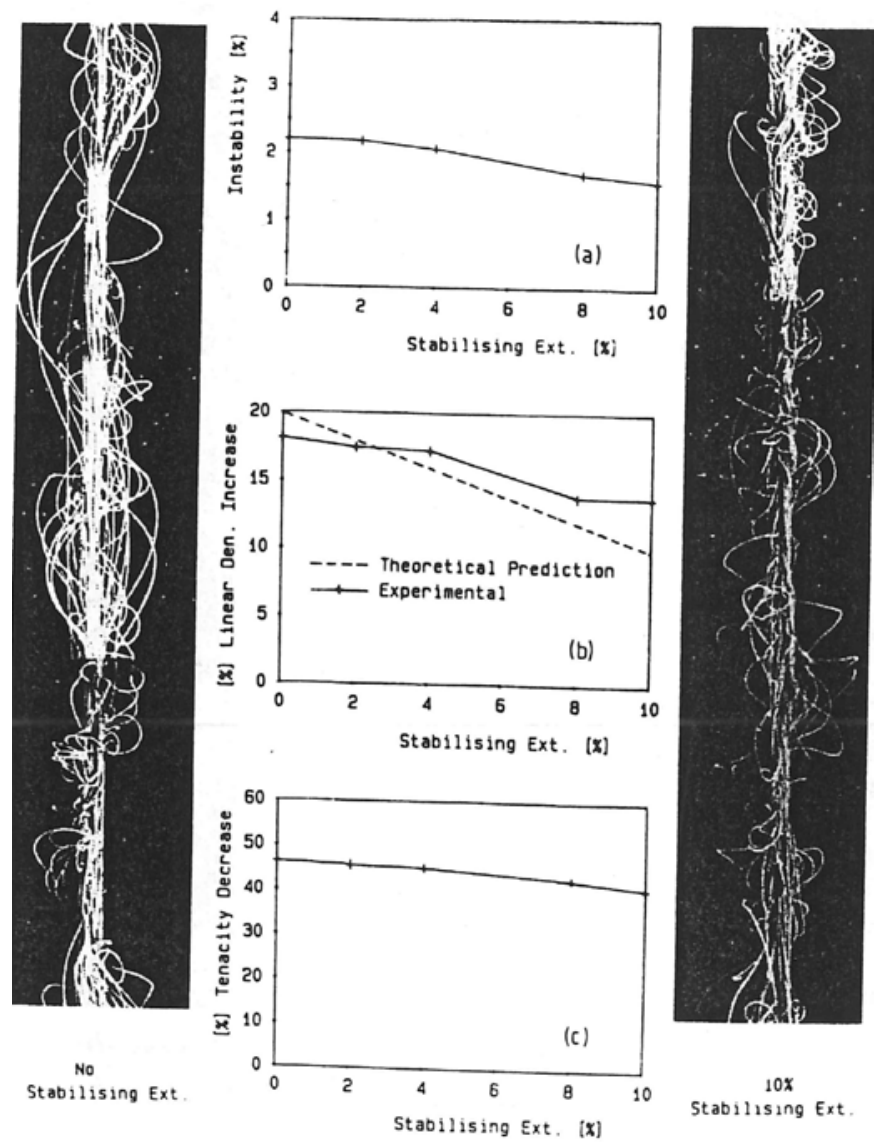

FIGURE 7. Effects of stabilizing extension on the properties of air-jet textured yarns.

\section{WET AND DRY PROCESSING AND USE OF AN IMPACT ELEMENT}

Applying water to the filaments prior to their entry to the nozzle is now a well-recognized requirement for better texturing. However, the use of impact elements in the form of cylindrical bars, spherical elements, or flat plates placed at the exit of the nozzle is only recommended for particular applications such as low linear density yarns or high-speed operations. Figure 8a shows that the instability increases with both wet processing and the use of a spherical impact element. Such increases, provided they are within acceptable limits, are indicative of improved yarn quality. The SEM photographs also support this argument, in that dry textured yarns exhibit larger and fewer loops than wet textured yarns, as do wet textured yarns with respect to yarns textured with the impact element.

Although an impact element is not essential, wetting the supply yarn prior to the nozzle is required. Recent research by Acar et al. [3] showed that the effect of water application is to reduce both the yam-to-solid surface and the interfilament friction. The minimum amount of water required was about 0.2 liters/hour, as opposed to the common industrial 
practice of 2 liters/ hour, such higher levels of water application contributing no further improvement to the process.

Texturing is enhanced by the water application, be- cause the overfed filaments are better entangled and surface loops are firmly fixed to the compact core of the yarn. This better entanglement causes only a small fraction of the linear density increase in the yarn to be lost under both the stabilizing and winding-up tensions (Figure 8b). Dry texturing, however, yields poor texturing because most of the loops and entanglements are removed under such tensions.

As seen in Figure 8c, when the yarn is dry textured at 9 bar air pressure, the texturing is so poor that only about $26 \%$ decrease in tenacity is observed, thus indicating little change from the basic straight filament supply yarn. When the yarn is wet textured at the same pressure, however, the decrease in tenacity, indicative of better texturing, goes up to about $48 \%$. The same trends can be observed at other air pressures, and Acar et al. claim this improved texturing effectiveness is due to reduced interfilament friction [3].
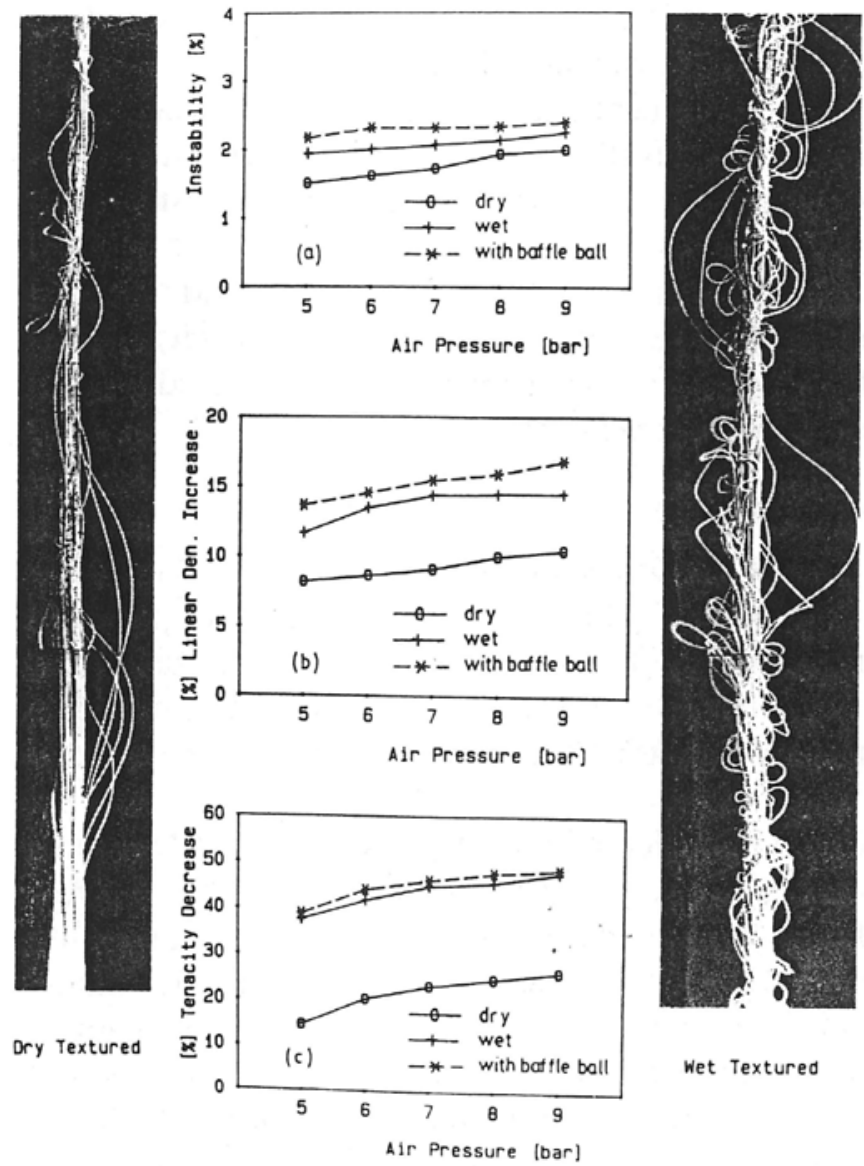

Wet Textured

FIGURE 8. Effects of wet texturing and use of an impact element on the properties of air-jet textured yarns.

The deployment of an impact element does not seem to make any further significant improvement in wet textured yarns. When we compared the linear densities of such textured yarns, we concluded that the impact element contributes little to the process, and the lack of a further significant reduction in the tenacity due to the use of an impact element adds further evidence to support this conclusion. 


\section{NOZZLE TYPE}

As far as the instabilities of the textured yarns are concerned, the T100 and T34 1 HemaJets produce similar yarns. The standard-core HemaJet produces yarns with reduced instability, whereas the yams textured by the Taslan type XIV nozzle possess the highest instability (Figure 9a). Nevertheless, the instabilities of the yarns produced by the four nozzles considered are in the same close range, particularly at high pressures (Figure 9a). Figure 9 also includes the typical SEM photographs of two yarns textured by T34 1 HemaJet and Taslan type XIV nozzles. The distinctive nature of the yarn textured by the Taslan XIV is that the large loops and arcs are dominant on the surface of the yarn, while the yarns textured by the HemaJets appear to possess greater numbers of smaller sized loops.
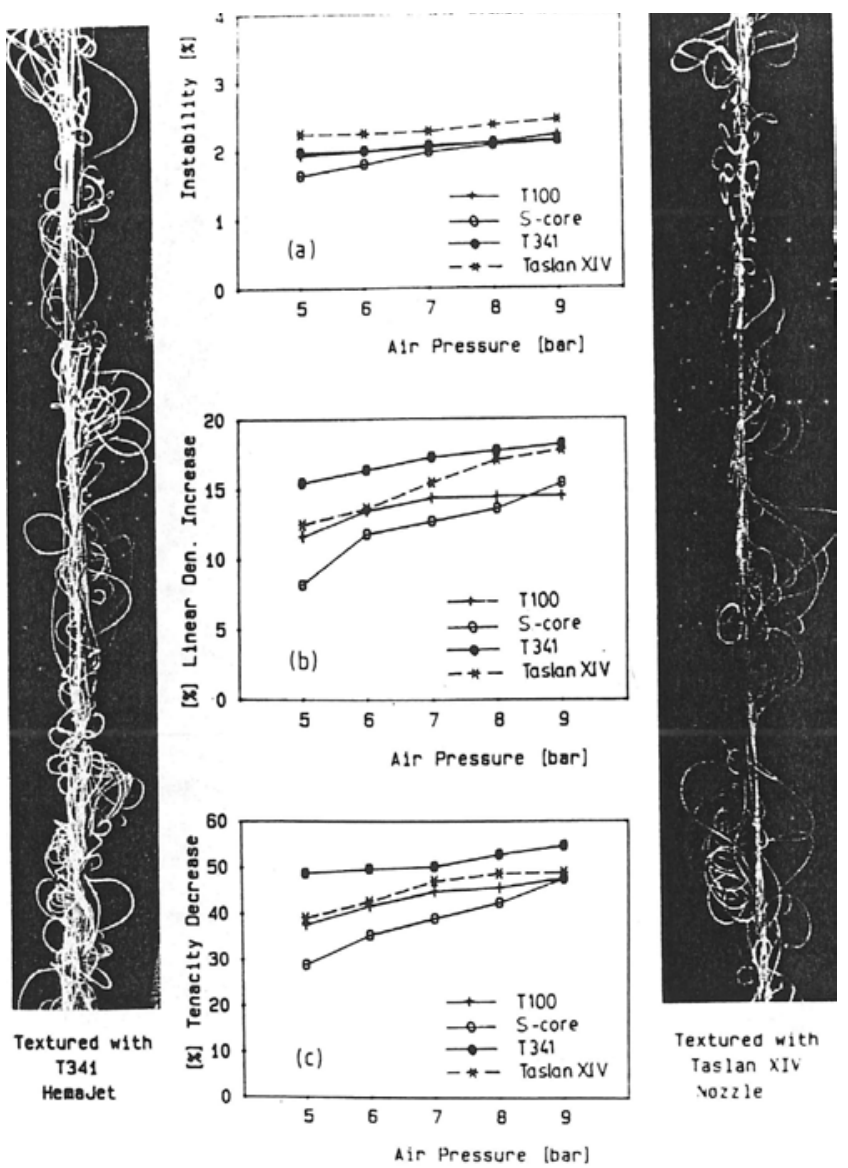

FIGURE 9. Effects of nozzle type on the properties of air-jet textured yarns.

Figure 9a, depicting similar instabilities for the yarns textured by the T100 and T341 HemaJets, suggests that these two yarns are of a similar quality. When their linear densities and tenacities are compared, however, one can appreciate that the two yarns produced by two different nozzles have different characteristics.

Figure 9b illustrates that the yarns textured by the T34l HemaJet attain the highest linear density corresponding to an increase of about $17 \%$. This clearly indicates that the overfed filaments are so effectively entangled that even a stabilizing extension of $4 \%$ has little adverse effect. This satisfactory texturing could beattributed to the higher air velocities achievable with this nozzle [6] at the cost of a greater compressed air consumption than the other nozzles. This argument is also supported by the result for the Taslan XIV nozzle, which possesses the second highest flow velocities. 
The strength test results indicate that the T34l HemaJet, which produces the highest air velocity, dis- plays the greatest decrease in tenacity, approximately $50 \%$ as seen in Figure 9c. Figures 9c and b demonstrate that the nozzles we considered show similar trends as far as the linear densities and strengths of the yarns are concerned. Their relative texturing effectiveness can be ranked in the following order: T342 HemaJet, Taslan XIV, T100, and standard-core HemaJet. The T100 HemaJet is more effective than the standard core HemaJet, despite its reduced air consumption and lower air velocities [6]. This can be attributed to its improved design, which is why the no longer produced standard-core HemaJets are regarded as obsolete by today's textile industry.

\section{MATERIAL}

We used two different polymer yarns, i.e., polyester and polyamide. The filament linear density and the number of filaments and hence the total linear density of these yarns were kept as close as possible, although there was no control over their cross-sectional shapes and the applied spin finishes. They were textured under reference conditions but at varying air pressures.

Figure 10 indicates that the polyamide yarn exhibits lower instability, slightly lower linear density increase, and lower percentage tenacity decrease. This shows that the texturability of the polyamide filament yarn seems to be less than that of the polyester filament yarn, al-though both can be textured effectively. This is also manifested by the presence of more undesirable parallel filaments in the core of the polyamide yarn as seen from the SEM photographs, but it could be that the difference in texturing quality is caused by differences in spin finish and filament cross section.
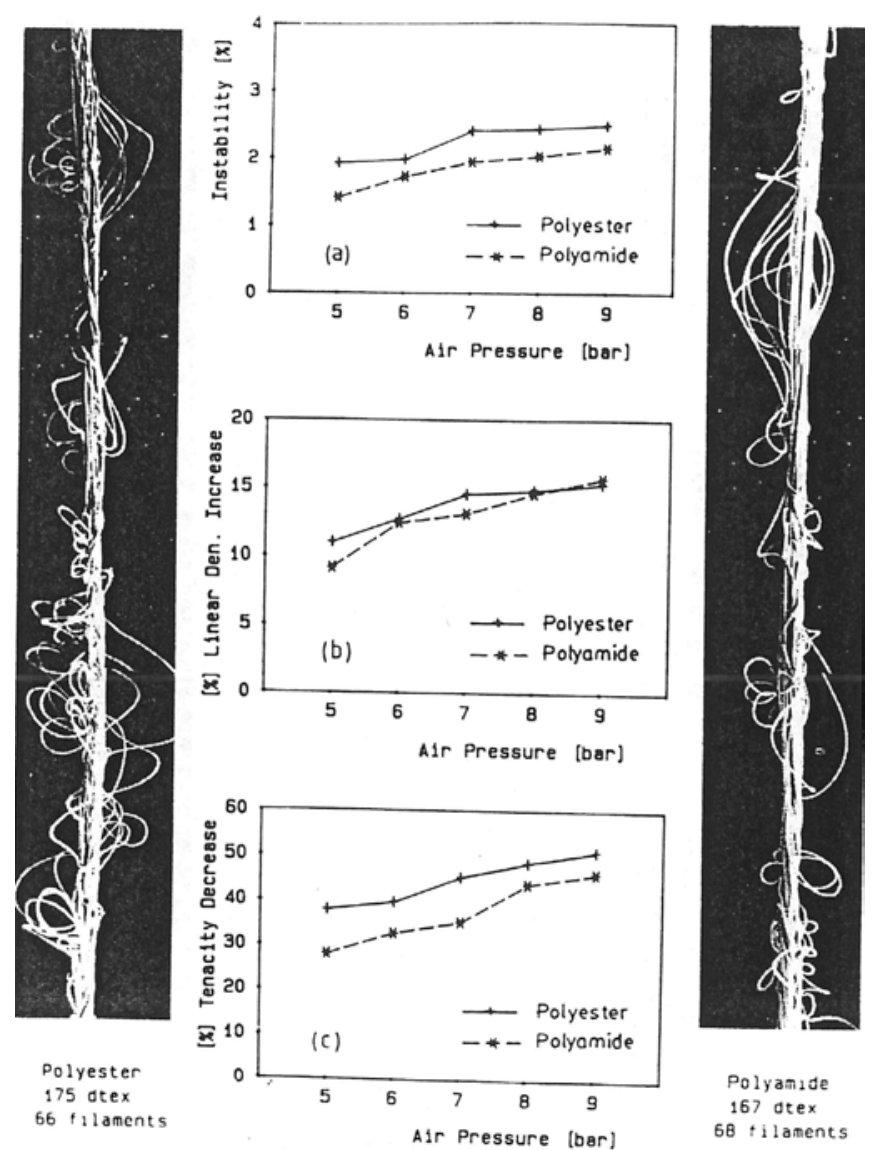

FIGURE 1 0. Effects of supply yam material on the properties of air-jet textured yams. 


\section{FILAMENT LINEAR DENSITY}

Supply yarns with approximately the same number of filaments but with varying filament linear densities were tested to analyze how this affected the textured yarn properties.

Acar et al. [2] have shown that the total drag force on the filaments is dependent on the surface and projected areas of the filaments in the air flow, and greater drag force acts on filaments with increased areas. It is also known that bending and torsional stiffnesses are directly proportional to the second moment of area about a diameter and to the polar second moment of area;-respectively. Therefore, we concluded that the smaller the second moments of areas, the smaller the forces and torques required to bend and twist the filament, respectively.

The findings and conclusions of Acar et al. showed that for an equal total yarn linear density, yarns consisting of finer filaments require smaller fluid forces to displace and entangle them than those consisting of coarser filaments. This is due to the reduced bending and twisting rigidities and increased surface and projected areas of finer filaments. Therefore we anticipated that finer filaments would be better textured.

This point is verified by Figures 11b and c, which show reductions in textured yarn linear density and in tenacity decrease with increasing filament linear density, thereby indicating that finer filaments produce better textured yarns.
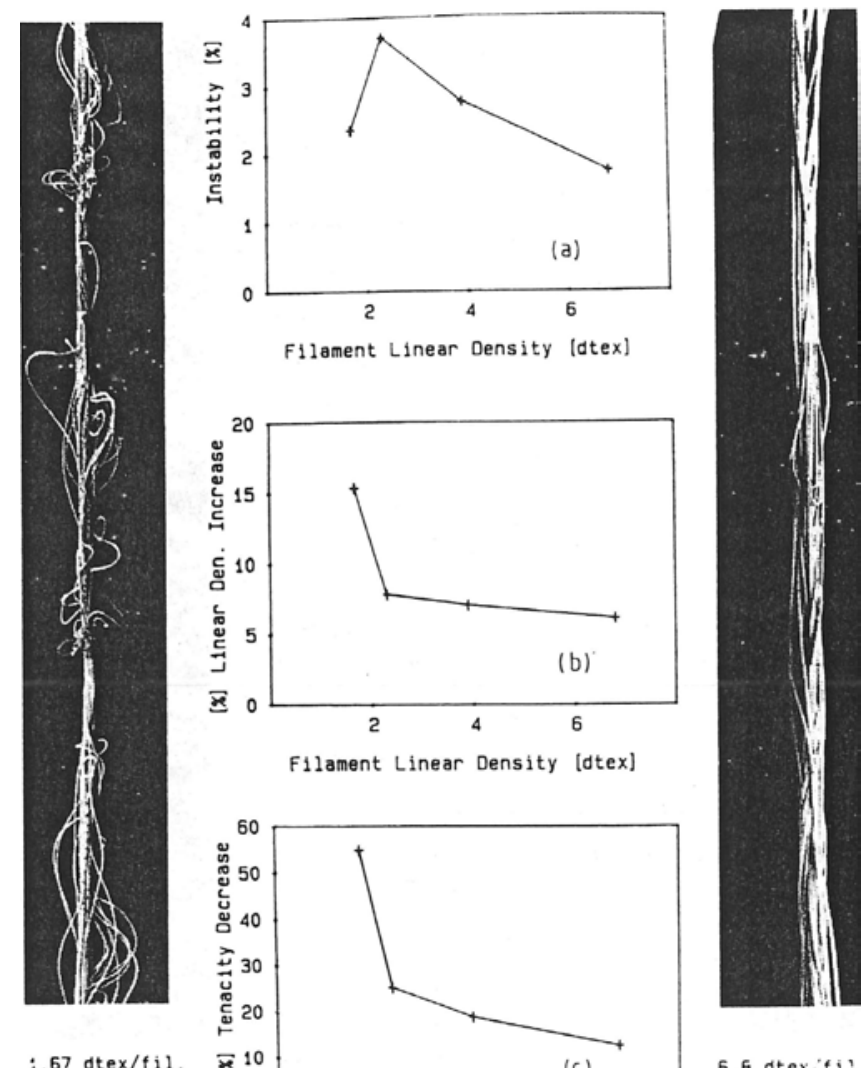

Filament Linear Density [dtex]

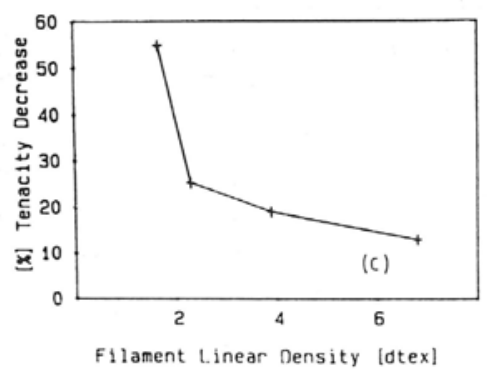

6.6 dtexifil

FIGURE 11. Effects of linear density per filament on the properties of air-jet textured yarns. 
On the other hand, the instability curve (Figure 11a) indicates an increase with the increasing linear density up to approximately 2 dtex and then displays a reduction. The low instability at the fine filament end of the range may be because of the enhanced texturing effect, which may give rise to the interfilament friction that holds the entangled filaments and loops together under the applied loads. As the filaments get coarser, the entanglement and loop formation deteriorate, producing yarns with fewer loops and poorly entangled cores and resulting in a reduction in yarn instability. This indicates that improved yarn stability can be obtained, together with improved loop and entanglement formation, if the individual filament linear density is kept below a certain value. For the particular conditions considered, the most suitable supply yarns for air-jet texturing should comprise filaments finer than 2 dtex linear density, but this could, of course, be different with other process and supply yarn parameters and with other texturing nozzles.

The better texturing obtained with finer filaments is also evident from the SEM photographs. Here the 1.67 dtex per filament yarn displays better entangled core and surface loops, whereas the 6.8 dtex per filament yarn has only mingled and disoriented filaments with virtually no loops present.

\section{NUMBER OF FILAMENTS}

As the number of filaments (total yarn linear density) increases, an enhancement in yarn quality is rightly expected because the potential for filament entanglement is increased. The experiments with different nozzle types have revealed, however, that this statement holds only for the number of filaments a particular nozzle design can texture effectively at given process conditions. When this optimum number of filaments is exceeded, a deterioration in yarn quality occurs for two reasons: first the air-flow is progressively more disturbed by the presence of increasing numbers of filaments, as is also true in the case of high overfeeds, and second because the increased number of loops arising from the presence of more filaments increases the likelihood of loops being pulled out under applied tension.

Figure 12 illustrates that for the T100 HemaJet at reference conditions, the optimum number of filaments is less than 66, for the particular 1.67 dtex per filament yarn (110 dtex/66 filaments) used.This optimum number is in the region of 198 filaments, however, giving 330 dtex total linear density when the T34l HemaJet nozzle is used at the same texturing conditions. This thereby verifies that some nozzles are more suitable than others for particular yarn and process conditions. (The optimum values may vary with the linear density per filament of the supply yarn.)

The measured yam properties all show reduced values of instability, percentage linear density increase, and percentage tenacity decrease as the total yam linear density is increased from 110 dtex to 440 dtex. Also a deterioration in loop and entanglement formation is shown in the SEM photographs of the yam with an increased number of filaments, although this yam would probably be acceptable for many end uses.

In conclusion, in addition to the linear density per filament, the number of filaments of the yam to be textured should always be borne in mind, together with other process and supply yam parameters, before a suitable nozzle is chosen from the range available. 

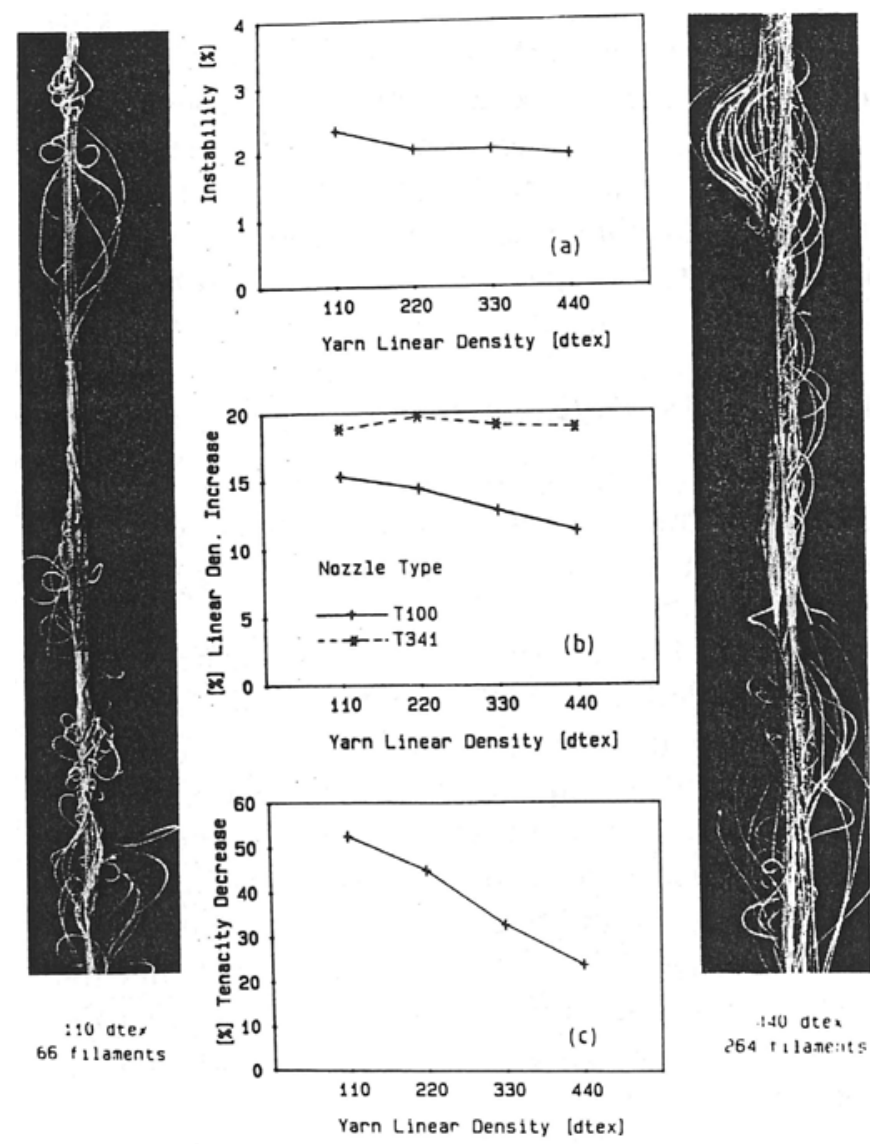

40 atex
64 it

FIGURE 12. Effects of total supply yarn linear density on the properties of air-jet textured yarns.

\section{Conclusions}

The properties, and in particular the instability, of air-jet textured yams are greatly influenced by altering the processing parameters. The supply yam properties also affect the final yam properties. The optimization of any given textured yam property almost always affects other yam characteristics, and therefore this must be borne in mind in selecting process and supply yam parameters for specific end uses.

The experimental results have revealed that the main process parameter that has a significant effect on the instability of the textured yam is the overfeed. The linear density of a particular yam can be increased by increasing the overfeed, by increasing the air pressure, by decreasing the process speed, by wetting the filament yam, and by deploying an impact element. Different nozzles produce textured yams with different properties from the same supply yams. As the stabilizing extension is increased beyond 4\%, the loops and bows are destroyed, and the instability of the yam is thus reduced. For the particular processing conditions used, polyester yams textured better than polyamide yams.

Our research has also suggested that a yam suitable for air-jet texturing should have a filament linear density less than 2 dtex. The possibility of air-jet texturing of supply yams with filament linear densities much higher than 2 dtex is indeed poor, because while they may exhibit slight increases in their yam linear densities after texturing, this only arises from the reorientation of the filaments in the yam core and the formation of large and unstable loops. Furthermore, we have shown that for a given texturing nozzle, there is an optimum number of filaments that can be textured most effectively. Therefore the nozzle type 
should be carefully chosen when a particular yam is to be textured.

\section{Literature Cited}

1. Acar, M., and Wray, G. R., An Analysis of the Air-Jet Yam Texturing Process, Part I, J. Textile Inst. 77 (1), 19-27 (1986).

2. Acar, M., Turton, R. K., and Wray, G. R., An Analysis of the Air-jet Yam Texturing Process, Part IV, J. Textile Inst. 77 (4), 247-254 (1986).

3. Acar, M., Turton, R. K., and Wray, G. R., An Analysis of the Air-jet Yam Texturing Process, Part V, 1. Textile Inst.77 (6), 359-370 (1986).

4. Bock, G., Texturing Filament Yams in an Air Flow- Tangling Mechanism, Int. Textile Bull. Spinning 4, 359- 389 (1981).

5. Demir, A., Acar, M., and Wray, G. R., Instability Tests for Air-jet Textured Yams, Textile Res.J1. 56 (3), 191- 202 (1986).

6. Demir, A., Acar, M., and Wray, G. R., An Improved Understanding of Modem Techniques for Air-jet Texturing of Continuous Synthetic Yams, in "The Proceedings of 4th International Textile Symposium," Izmir, Turkey, 1986, pp. 131, 164.

7. Dupont, Taslan Jet, Type XIV and XV, Information Leaflet, E. I. du Pont de Nemours and Co.

8. Fischer, K., Air-jet Texturing, Int. Textile Bull. Spinning 5, 287-292 (1980).

9. Fischer, K., and Wilson, D. K., Air-jet Texturing - An Alternative to Spun Yam Production, in "Textile Machinery: Investing for the Future," The Textile Institute, Manchester, England, 1982.

10. HemaJet Air Texturing Jet Manual, Heberlein Maschinenfabrik AG, Switzerland, 1981.

11. Jet Cores Leaflet, Series T, T100, T31l, T341, T1 10, Tl40, T351, Heberlein Maschinenfabrik AG, Switzerland, 1985.

12. Kollu, T., Air-jet Textured Yarns, Doctoral thesis, UMIST, Manchester, 1985.

13. Piller, B., Development Trends in the Production of Air- jet Texturized Filament Yarns with Spun Yam Character, Melliand Textilber. Eng. Ed. 60 (2), 128-136 (1979).

14. Rozmarynowska, K., and Godek, J., Effects of Processing Variables on the Properties of Air-bulked Yams, in "Bulk Stretch and Texture," The Textile Institute, Manchester, England, 1966, pp. 39-41.

15. Wilson, D. K., Apparel Fabrics - What Chances Have Air-jet Textured Yarns, Textile Inst. Ind. 17, 170-174 (1979).

16. Wray, G. R., The Properties of Air-textured Yams, J. Textile Inst. 60 (3), 102-126 (1969). 